\title{
Percepções de alunas de Ensino Médio sobre as subáreas da Computação
}

\author{
Karen da Silva Figueiredo ${ }^{1}$, Rayane Vitorassi ${ }^{2}$, Edeizi Monteiro ${ }^{3}$, Suliane de \\ Oliveira Carneiro ${ }^{4}$
}

Instituto de Computação - Universidade Federal do Mato Grosso (UFMT)

Cuiabá, Mato Grosso, Brasil ${ }^{123}$

Instituto Federal de Mato Grosso (IFMT), Campus Pontes e Lacerda

Pontes e Lacerda, Mato Grosso, Brasil ${ }^{4}$

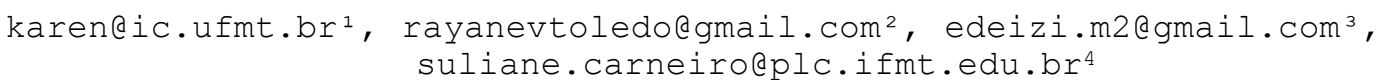

\begin{abstract}
The present work presents a preliminary research with high school female students of Mato Grosso about their level of information with respect to the subareas of computing and their level of interest in learning more about these subareas.
\end{abstract}

Resumo. O presente trabalho apresenta uma pesquisa preliminar realizada com alunas de ensino médio de uma escola do interior do Mato Grosso com objetivo de medir o nível de informação das alunas a respeito das subáreas da computação e o seu nível de interesse em conhecer mais sobre estas subáreas.

\section{Introdução}

Dados do INEP revelam que no Brasil, desde 1991, as mulheres perderam 19,37\% da representatividade em cursos de ensino superior relacionados à área de Computação, totalizando, apenas, $15,53 \%$ do quantitativo de alunos matriculados [INEP 2015]. Diversas pesquisas acadêmicas e da mídia procuram compreender o porquê do baixo ingresso de jovens mulheres nestes cursos [Ahuja 2002, Figueiredo e Maciel 2016].

Um dos fatores apontados para um número inexpressivo de mulheres na computação deve-se à falta de informação das jovens em geral sobre a carreira, áreas de concentração e diferenças entre os cursos de Computação [ICMC/USP 2014]. As jovens seriam ainda mais afetadas quando se leva em consideração a falta de incentivo social para atuarem com tecnologia [Verbick 2002].

No Brasil, a Sociedade Brasileira de Computação (SBC) designa comissões especiais que reúnem associados com interesses comuns em determinada subárea da Computação, resultando na categorização de 27 subáreas da computação [SBC 2017]. Muito embora os cursos de graduação em computação abordem tais subáreas (alguns de forma mais profunda e outros menos), não é comum que todas as subáreas sejam popularmente divulgadas ou discutidas nas escolas, na mídia e nos círculos sociais de jovens alunas de ensino médio, que estão em fase de ponderamento sobre qual carreira e/ou curso seguirem após a conclusão dos anos escolares. 
Desta forma, este artigo apresenta uma pesquisa preliminar - realizada com alunas de ensino médio de uma escola do interior do estado de Mato Grosso com o objetivo de medir o nível de informação acerca das subáreas da computação e o nível de interesse em conhecer mais sobre as diversas subáreas. Nas seções a seguir são apresentadas a metodologia, resultados e considerações desta pesquisa.

\section{Metodologia}

A presente pesquisa foi realizada com 35 alunas de ensino médio ${ }^{1}$ do Instituto Federal de Mato Grosso na cidade de Campus Pontes e Lacerda em abril de 2015, durante uma atividade do projeto Meninas Digitais Regional Mato Grosso. O projeto Meninas Digitais Regional Mato Grosso tem como objetivo a realização de práticas de caráter motivacional e informativo com alunas de Ensino Médio no estado de Mato Grosso visando a equidade de gênero nas carreiras e cursos das áreas de Computação e Tecnologias da região através do incentivo e promoção da participação feminina [Figueiredo et al. 2016].

As alunas participantes da atividade possuem idade entre 14 e 19 anos, compreendendo todos os anos do ensino médio, sendo algumas também alunas de nível técnico nos seguintes cursos: Manutenção e Suporte em Informática (17 alunas), Controle Ambiental (9 alunas) e Secretariado (4 alunas). A pesquisa foi realizada por meio de questionário e, logo após, foi feita uma dinâmica, com o objetivo de discutir as principais diferenças entre os cursos superiores de computação e suas possibilidades de atuação. Por fim, realizou-se um debate acerca da interação das jovens com as tecnologias que consomem no dia-a-dia.

O questionário aplicado continha as 27 subáreas da Computação listadas em formato de grade e as seguintes opções para resposta: "Não conheço e nunca ouvi falar", "Não conheço, mas já ouvi falar", "Conheço POUCO e tenho interesse em estudar mais sobre o tema", "Conheço POUCO e NÃO tenho interesse em estudar mais sobre o tema", "Conheço MUITO e tenho interesse em estudar mais sobre o tema", "Conheço MUITO e NÃO tenho interesse em estudar mais sobre o tema" e "Não sei avaliar o meu interesse".

\section{Resultados}

As 27 subáreas da computação dispostas nos questionários, conforme a SBC as divide são: Algoritmos, Arquitetura de Computadores, Banco de Dados, Biologia Computacional, Combinatória e Otimização, Computação Aplicada a Saúde, Computação Gráfica e Processamento de Imagens, Computação Musical, Concepção de Circuitos e Sistemas Integrados, Engenharia de Sistemas Computacionais, Engenharia de Software, Geoinformática, Informática na Educação, Inteligência Artificial e Inteligência Computacional, Interação Humano Computador, Jogos e Entretenimento Digital, Linguagens de Programação, Métodos Formais, Processamento de Linguagem Natural, Realidade Virtual, Redes de Computadores e Sistemas Distribuídos, Robótica, Segurança de Informação e de Sistemas Computacionais, Sistemas Colaborativos,

\footnotetext{
${ }^{1}$ Previamente autorizadas pelos responsáveis a participarem.
} 
Sistemas de Informação, Sistemas Multimídia e Web e Sistemas Tolerantes a Falhas [SBC 2017].

As subáreas apontadas com maior desconhecimento (opções "Não conheço e nunca ouvi falar" e "Não conheço, mas já ouvi falar",) pelas participantes foram: Biologia Computacional (82,9\%), Geoinformática (80\%), Processamento de Linguagem Natural (80\%), Métodos Formais (77,2\%), Combinatória e Otimização (77,1\%), Sistemas Tolerantes a Falhas $(77,1 \%)$, Sistemas Colaborativos $(74,3 \%)$, Computação Aplicada a Saúde (74,3\%), Realidade Virtual (62,9\%) e Engenharia de Sistemas Computacionais (60\%). Geoinformática, Combinatória e Otimização foram as subáreas mais indicadas como totalmente desconhecidas, respectivamente $65,7 \%$ e $60 \%$.

As subáreas assinaladas como mais conhecidas pelas participantes, isto é, subáreas que as participantes indicaram conhecer de alguma forma, foram (opções "Conheço POUCO e tenho interesse em estudar mais sobre o tema", "Conheço POUCO e NÃO tenho interesse em estudar mais sobre o tema", "Conheço MUITO e tenho interesse em estudar mais sobre o tema" e "Conheço MUITO e NÃO tenho interesse em estudar mais sobre o tema"): Jogos e Entretenimento Digital (74,3\%), Algoritmos (60\%), Linguagens de Programação (60\%), Inteligência Artificial e Inteligência Computacional (57,2\%), Robótica (57,2\%), Banco de Dados (57,1\%), Informática na Educação $(57,1 \%)$ e Sistemas de Informação (51,4\%).

As subáreas informadas como mais interessantes (opções "Conheço POUCO e tenho interesse em estudar mais sobre o tema" e "Conheço MUITO e tenho interesse em estudar mais sobre o tema") foram: Inteligência Artificial e Inteligência Computacional (48,6\%), Robótica (48,6\%) e Jogos e Entretenimento Digital (45,7\%); já as subáreas menos interessantes (opções "Conheço POUCO e NÃO tenho interesse em estudar mais sobre o tema" e "Conheço MUITO e NÃO tenho interesse em estudar mais sobre o tema") segundo as participantes são: Arquitetura de Computadores, Engenharia de Software e Algoritmos, todas com 28,6\% das respostas. As subáreas mais conhecidas e interessantes, de acordo com as respostas foram: Informática na Educação, Linguagens de Programação e Jogos e Entretenimento Digital, todas com 14,3\%.

Nota-se que as subáreas menos conhecidas pelas alunas são mais específicas, de conhecimento mais avançado, geralmente abordadas de forma profunda em cursos de pós-graduação e disciplinas de tópicos avançados na graduação, enquanto as subáreas mais conhecidas são áreas mais retratadas pela mídia e mais próximas do cotidiano das alunas, principalmente, das que fazem o curso técnico em Manutenção e Suporte em Informática. Enquanto, as subáreas mais interessantes são áreas mais lúdicas e as menos interessantes são subáreas mais técnicas, provavelmente com mais conhecimento por meio da formação das participantes.

A tabulação de todas as respostas da pesquisa pode ser encontrada no endereço: https://goo.gl/J7Qtr8.

\section{Considerações Finais}

O presente trabalho apresentou os resultados de uma pesquisa acerca das percepções de alunas sobre os níveis de informação a respeito das subáreas da computação e o seu interesse em conhecer mais sobre elas. A partir dos dados relatados, foi possível 
perceber que as jovens tendem a interessar-se por subáreas mais lúdicas e mais difundidas pela mídia, desde reportagens a filmes sobre o assunto. Assim, investir em realizar atividades motivacionais e capacitativas com as alunas de ensino médio sobre tais subáreas pode despertar mais o interesse dessas jovens em realizar um curso superior em computação ou área afim.

Compreende-se que esta é uma pesquisa preliminar, que pode ser estendida para ter resultados mais sólidos, incluindo também perguntas dissertativas.

A pesquisa também pode ser aplicada com um número maior de participantes, inclusive com alunas de ensino superior. A realização desta pesquisa com alunas de cursos de graduação em computação, poderia ajudar a entender melhor os seus interesses para poder desenvolver estratégias curriculares com intuito de evitar a evasão destas alunas ao longo do curso.

\section{Referências}

Ahuja, M. K. (2002) "Women in the information technology profession: A literature review, synthesis and research agenda", European Journal of Information Systems, v. 11, n. 1 , p. $20-34$.

Comunidade Brasileira de Sistemas de Informação (2015) "Saiba de uma vez por todas as diferenças entre os cursos superiores de TI", Artigo de Cláudio Florenzano, Disponível em: http://www.cbsi.net.br/2015/06/as-diferencas-entre-os-cursos-deTI.html\#.VirQoSudBwB, Acesso: 23 de março de 2017.

Figueiredo, K.; Maciel, C. (2016) "Reflexões sobre Gênero, Tecnologia e Processo Vocacional", $10^{\circ}$ WIT - Women in Information Technology, XXXVI Congresso da Sociedade Brasileira de Computação, p. 2728- 2731.

Figueiredo, K.; Neto, P. C. da S., Maciel, C. (2016) "Meninas Digitais Regional Mato Grosso: Práticas Motivacionais no Ensino Médio para a Equidade de Gênero nas Carreiras e Cursos de Computação e Tecnologias", $10^{\circ}$ WIT - Women in Information Technology, XXXVI Congresso da Sociedade Brasileira de Computação, p. 2702- 2705.

ICMC/USP (2014) "A difícil escolha entre Ciências de Computação, Engenharia de Computação e Sistemas de Informação", Artigo de Denise Casatti, Disponível em: http://conteudo.icmc.usp.br/Portal/Noticias/leituraNoticias.php?id_noticia=526\&tip oPagina=Noticias\&tipoNoticia=Ensino, Acesso: 23 de março de 2017.

INEP (2015) "Resumo Técnico da Educação Superior 2013”, Diertoria de Estatísticas Educacionais DEED, Instituto Nacional de Estudos e Pesquisas Educacionais Anísio Teixeira, Brasília-DF, 82 p.

SBC (2017) "Sociedade Brasileira de Computação - Comissões Especiais", Página da Web, Disponível em: http://www.sbc.org.br/403-comissoes-especiais, Acesso: 23 de março de 2017.

Verbick, T. (2002) "Women, technology, and gender bias", Journal of Computing Sciences in Colleges, v. 17, n. 3, p. 240-250. 